\title{
El ser y su ser en Tomás de Aquino*
}

The Being and his Being in Thomas Aquinas

Recibido: 19 de agosto de 2008 - Revisado: 2 de octubre de 2008 - Aceptado: 20 de enero de 2009

Liliana Beatriz Irizar**

\section{Resumen}

Dos prestigiosos filósofos, Enrico Berti y Anthony Kenny, sostienen que Tomás de Aquino manifiesta importantes inconsistencias doctrinales, especialmente en su doctrina sobre Dios entendido como ipsum esse subsistens.

En el contexto de esta discusión, el presente artículo tiene como objetivo principal retomar los textos más relevantes en los que el Aquinate aborda el tema del ser de Dios y lo llama ipsum esse subsistens así como los pasajes en que habla del ser de Dios como su ser (suum esse). Esto con el fin de establecer si efectivamente es justo identificar el ipsum esse subsistens con la idea de Dios considerado como el ser separado de inspiración platónica.

Este estudio permitirá, asimismo, precisar en qué medida es válido afirmar que la filosofía de Aquino es una filosofía negativa y su metafísica una metafísica mínima.

\section{Palabras clave}

Teología negativa, metafísica mínima, ser de Dios; ipsum esse subsistens, Tomás de Aquino.

\begin{abstract}
Two prestigious philosophers, Enrico Berti and Anthony Kenny, assert that Thomas Aquinas expresses relevant doctrinal incoherencies, especially in his ipsum esse subsistens doctrine.

In the context of this discussion, the current article intends to review the most outstanding texts where Aquinas considers the being of God issue, and calls Him ipsum esse subsistens, as well for the passages in which he talks about the being of God as his being (suum esse). The aforesaid, is aimed to establish if effectively is fair to identify the ipsum esse subsistens with the idea of God considered as the separated being from Platonic inspiration.

This analysis will allow us to precise to what extent is valid to affirm that the Aquinas' philosophy is a negative philosophy and his metaphysics is minimum metaphysics.
\end{abstract}

\section{Key words}

Negative Theology; minimum Metaphyscis; being of God; ipsum esse subsistens; Thomas Aquinas.

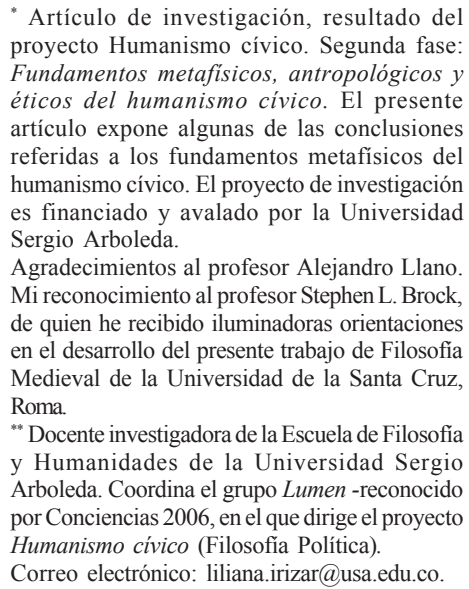

*Artículo de investigación, resultado de proyecto Humanismo cívico. Segunda fase: Fundamentos metafisicos, antropológicos $y$ éticos del humanismo cívico. El presente artículo expone algunas de las conclusiones referidas a los fundamentos metafísicos del humanismo cívico. El proyecto de investigación es financiado y avalado por la Universidad Sergio Arboleda.

Agradecimientos al profesor Alejandro Llano. Mi reconocimiento al profesor Stephen L. Brock, de quien he recibido iluminadoras orientaciones en el desarrollo del presente trabajo de Filosofía Medieval de la Universidad de la Santa Cruz, Roma.

${ }^{* *}$ Docente investigadora de la Escuela de Filosofía y Humanidades de la Universidad Sergio Arboleda. Coordina el grupo Lumen -reconocido por Conciencias 2006, en el que dirige el proyecto Humanismo cívico (Filosofía Política).

Correo electrónico: liliana.irizar@usa.edu.co. 


\section{Problema de investigación y método}

¿La doctrina de Tomás de Aquino, la cual considera a Dios como el ipsum esse subsistens, es equiparable a la sustancialización del ser y de lo uno tal como los concibió Platón? ¿Cómo es preciso entender dicha expresión del Aquinate? ¿El tomismo, en general, no ha dado lugar a que se interprete la fórmula ipsum esse como una sustancialización del ser? ¿Qué novedad aportan a la interpretación de dicha doctrina del Aquinate autores como Inciarte, Llano, Brock o Dewan?

Con miras a resolver dichos interrogantes se ha recurrido al método expositivo analítico. El desarrollo argumentativo se basa esencialmente en el pensamiento metafísico de Tomás de Aquino. Asimismo, han resultado un elemento clave para el análisis de los textos de Aquino, algunas obras de importantes tomistas que se han ocupado del tema, como Fernando Inciarte, Alejandro Llano, Stephen L. Brock y Lawrence Dewan.

A partir de la bibliografía apuntada, luego de una lectura atenta de las críticas dirigidas contra Tomás de Aquino en este punto, se ha procedido, en primer lugar, a analizar el planteamiento fundamental realizado por dicho filósofo. De modo paralelo se han leído los comentarios sobre su obra en este tema preciso por parte de los autores mencionados.

En un segundo lugar, se han expuesto de manera sistemática las principales críticas recientes realizadas contra la doctrina aquiniana del ipsum vesse, y simultáneamente se han presentado lo que se considera una visión más ajustada y correcta del pensamiento de Tomás de Aquino. Para articular las críticas y su refutación se ha respetado el rigor científico propio de la argumentación filosófica.

\section{Introducción}

Doctrina del ipsum esse subsistens y el platonismo de Tomás de Aquino

En un artículo publicado en 2004, Stephen Brock (Brock, 2004) rehabilitaba un tema recurrente tanto entre los más avezados seguidores de Tomás de Aquino, así como entre los mayores representantes del aristotelismo contemporáneo.

Nos referimos a la discusión, siempre vigente, entorno al presumible platonismo del Aquinate. Un debate que básicamente ha girado y gira alrededor de cuáles son los alcances de la influencia del platonismo y del neoplatonismo en la filosofía de Santo Tomás, de modo especial, en su metafísica.

En el ensayo citado, Brock rescata un aspecto puntual de esta discusión, en el que han coincidido Enrico Berti y Antonny Kenny. La inquietud fundamental de ambos se relaciona con lo que podríamos denominar la inconsistencia conceptual de la metafísica de Tomás de Aquino. En efecto, si bien Tomás ha rechazado reiterada y explícitamente la teoría platónica de las Ideas en pleno acuerdo con la crítica aristotélica a la misma, por otro lado, se puede constatar que, no obstante, la adopta en puntos cruciales de su filosofía. De acuerdo con ambos filósofos, el Aquinate resultaría, por tanto, incoherente (Brock, 2004).

Por la vinculación que guarda con el objetivo de nuestro trabajo, nos limitaremos a resaltar aquí sólo un aspecto de la crítica mencionada: el relacionado con la doctrina del ipsum esse subsistens.

Según Berti, la conocida doctrina de Tomás de Aquino del ipsum esse subsistens, es decir, un ens per essentiam, cuya substantia es el mismo esse, restablecería la tesis platónica de la sustancialización del ser y de lo uno. Esto es, Santo Tomás, a la hora de fundamentar su doctrina del ser de Dios, se apartaría ostensiblemente de la metafísica de Aristóteles aproximándose, en cambio, a la posición platónica y neoplatónica, lo cual aparece manifiesto, observa Berti, si se tiene en cuenta que los instrumentos lógicos utilizados por la escolástica para esclarecer filosóficamente el concepto de creación no fueron precisamente aristotélicos, sino "el concepto platónico (y neoplatónico) de participación 
que Aristóteles había rechazado explícitamente" (Berti, 1979, p. 118).

Pero su alejamiento radical de Aristóteles se observa, precisamente, en la tesis del ipsum esse. Si hay un ser cuya esencia está constituida por su mismo ser, entonces el ser mismo es una sola esencia. Se echa por tierra así la analogía del ente; la diversidad intrínseca de los entes defendida por Aristóteles desaparece. En efecto, si la naturaleza del ente deriva del ser y lo que el ser principalmente significa, es la esencia de una única cosa, entonces la naturaleza del ente será ajena, extrínseca a la esencia de las demás cosas. El significado intrínseco del ente no incluirá la diversidad de las cosas. En suma, aunque Tomás de Aquino habla de analogía, en realidad haría del ser algo uniforme y unívoco (Brock, 2004).

Por otra parte, como ha advertido también S. Brock (Brock, 2004) para Berti el ipsum esse no sólo es anti-aristotélico sino que además pone en juego la trascendencia divina. Si la esencia de Dios es el ser mismo, entonces no sería rigurosamente propia, no le pertenece a él de modo exclusivo. Al igual que la Idea platónica, el ipsum esse es la versión separada del ser, es decir, algo uniforme y unívoco común a todas las cosas que participan de él (Berti, 2001).

En opinión de Berti, los términos que usa Tomás para distinguir el ser de Dios del ser de las criaturas, parecen indicar sólo una diversidad de condiciones de esta esencia: "separada en lugar de inherente, subsistente en vez de participada, infinita en vez de finita. No indica una diversidad intrínseca, diversidad respecto de lo que es el ser mismo (diversità in che cos'è l'essere stesso)" (Brock, 2004, pp. 199-200). Dicho en pocas palabras, para Berti, Santo Tomás “... está convirtiendo el esse en una 'esencia' única que, a su vez, sería la esencia de Dios" (Brock, 2007a).

Las imputaciones de Kenny en Aquinas on Being se encaminan en la misma dirección y son, incluso, más contundentes. Cabe resaltar que tal como han advertido algunos críticos de Aquinas on Being, gran parte de esta obra contiene un análisis crítico de la doctrina del ipsum esse sobre la base de categorías fregeanas a la luz de las cuales, Kenny juzga a Tomás falto de un reconocimiento suficiente de la distinción entre ser y existencia (Kenny, 2002).

En efecto, parece empeñado en interpretar a Tomás de Aquino como si éste fuera un "fregeano defectuoso" (Davies, 2005, p. 127). De hecho, su errónea comprensión, al menos en este punto, constituye precisamente la raíz de todas las equivocaciones cometidos en su análisis del Aquinate (Klima, 2004; McGinnis, 2005).

El núcleo de la crítica lanzada por Kenny contra la doctrina del ipsum esse subsistens, se condensa en la siguiente frase: "si esse aquí es existencia, ¿qué hacemos con la noción esse subsistente? Parece un absurdo decir de algo que su esencia es pura existencia" (Kenny, 2002, p. 41). Es importante tener presente que Kenny se está refiriendo aquí al pasaje de Ente et essentia donde Santo Tomás enseña que las formas simples, aunque sean forma sin materia, no son acto puro, pues son compuestas de acto (esse) y potencia (quiditas). Dios, en cambio, puesto que es sólo ser, de modo que su ser mismo es subsistente, no recibe adición de diferencia alguna (Tomás de Aquino, trad. 2001a, 4).

Es Lawrence Dewan quien magistralmente ha evidenciado las inconsistencias encerradas en las tesis de Kenny. Mediante un minucioso análisis de las mismas, el profesor Dewan (Dewan, 2005) ha demostrado rigurosamente que las descaminadas interpretaciones del autor entorno a los planteamientos del Aquinate, obedecen en último término al fracaso de Kenny en apreciar la distinción fundamental que Tomás establece entre el esse que designa el acto o perfección de la esencia y esse como predicado existencial. En efecto, Kenny no ha comprendido la doctrina del ser de Santo Tomás, menos aun podía asimilar de manera acertada su doctrina del ser de Dios (Dewan, 2005).

Para los fines de este trabajo, resulta particularmente significativa la interpretación que hace 
Kenny de la tesis según la cual Dios, a diferencia de las criaturas, no está limitado por ninguna perfección determinada, sino que incluye todas las perfecciones (Tomás de Aquino, trad. 2001b, 29.3). A juicio del filósofo oxoniense, la idea subyacente en dicho texto no es tanto que el esse de las criaturas es limitado como que el esse es limitado al ser recibido por las criaturas. El ser aparece entonces como un enorme depósito de líquido que va tomando la forma de los recipientes en donde es vertido. Así, algún esse se manifiesta con la forma de elefante, otro con la de tábano. Y concluye que tal fantasía es ciertamente platónica, indigna de la posición anti-platónica que Tomás de Aquino defiende de manera oficial (Kenny, 2002).

Cabe advertir que esta última aseveración de Kenny no es más que una ironía, puesto que el autor está muy convencido de que esa es la tesitura no sólo de Platón, sino del Aquinate.Así lo corrobora páginas más adelante en su comentario al pasaje Q.D. De Potentia, a.7, q. 5, donde Tomás de Aquino escribe que el nombre más propio de Dios es: Qui est (El que es) y añade, "porque [este nombre] no determina alguna forma para Dios, sino que significa esse indeterminadamente. $Y$ esto es lo que dice San Juan Damasceno, que 'El que es' significa el océano infinito de la sustancia" (Tomás de Aquino, 2000-2009e, 7.5). Una metáfora que sugiere, según la interpretación de Kenny, que el ser es una enorme reserva de líquido que toma una forma particular cuando es recibida en varios recipientes. "Tú y yo, las hormigas y los planetas, son pequeños cubos de este fluido universal; Dios es el enorme, ilimitado océano sin límites" (Kenny, 2002, p. 123).

En el desarrollo de Aquinas on Being el autor reitera una y otra vez su convicción de que en Tomás de Aquino se encuentra con frecuencia una combinación de un explícito anti-platonismo mezclado con un clima de ideas propio, únicamente del platonismo (Kenny, 2002). Un enigma que, concluirá más adelante Kenny, se puede resolver sólo si asumimos que el Aquinate es aristotélico en la Tierra y platónico en el cielo.
Aunque el autor reconoce la existencia de contextos doctrinales donde el Aquinate explica mejor el significado de la expresión Deus est ipsum esse subsistens y, según esto podríamos explorar otras maneras de interpretar la fórmula: "God just plain is, period". No obstante, para Kenny el problema central sigue en pie, ya que la cuestión fundamental es, según él, si esas ideas quedan bien expresadas diciendo que la esencia de Dios es su ser (Kenny, 2002).

Los términos del debate, presentado aquí en sus líneas generales, ofrecen el contexto apropiado para aproximarse al núcleo temático del presente ensayo. Tal como hemos indicado, la discusión entorno al platonismo de Santo Tomás, no es un asunto nuevo, pero tampoco es la intención de este escrito entrar en ella. Hemos querido traer estas dos críticas porque refuerzan lo que constituye una de los propósitos centrales de nuestra investigación. Nos proponemos indagar hasta qué punto algunas lecturas platonizantes del ipsum esse realizadas dentro del ámbito del tomismo, han conducido casi inevitablemente a este tipo de exégesis. Pensamos que, de hecho, existe la tendencia a explicar la doctrina de Santo Tomás respecto del ser de Dios acudiendo a una terminología que evoca el principio platónico de la perfección separada.

Asimismo, interesa resaltar un hecho que no deja de ser sorprendente. Asombra realmente el que las acusaciones levantadas tanto por Berti como por Kenny hayan despertado contadas reacciones entre los seguidores del Aquinate. Afortunadamente dos de los filósofos tomistas que han tomado parte en este debate-S.L. Brock y L. Dewan- lo han hecho a través de magníficos análisis que se seguirán muy de cerca en este trabajo.

En los apartados que siguen haremos referencia a algunas lecturas del ipsum esse subsistens, que de alguna manera han conducido a que se interprete dicha expresión en términos de el ser separado de filiación platónica. A continuación se presentan los análisis que 
consideramos más en sintonía con el pensamiento de Tomás de Aquino. Por último, y a modo de conclusión, indicaremos el nexo que existe entre una explicación del esse divinum más en sintonía con su filosofía del ser y la metafísica del Aquinate entendida como metafísica mínima.

\section{Ipsum esse subsistens: ¿el "ser separado”?}

Las explicaciones tradicionales del ipsum esse subsistens no siempre han logrado expresar del modo más apropiado el significado contenido en dicha fórmula. Con seguridad, se trata más de una dificultad de expresión que de un problema de comprensión por parte de los grandes comentaristas del Aquinate. En efecto, constituye un punto decisivo de este debatido tema la mayor o menor precisión con que se exprese lo que entiende Santo Tomás al afirmar que Dios es el ipsum esse subsistens, o que es su ser, o bien, que es esse purum. Porque, tal como comenta el profesor Brock, el propio Kenny concede que si Tomás con esa expresión quiere significar que Dios es un esse mismo, no el puro ser mismo, sino su propio ser mismo, en ese caso, puede evitar el platonismo (Brock, 2006).

En orden a discernir los elementos de la metafísica del Aquinate que podrían asociarse con la filosofía de Platón, se retomará brevemente la noción platónica de perfección separada. De acuerdo con la versión que trae Aristóteles en la Metafísica (Aristóteles, trad. 1994, I, 987 a30 989 a15), para Platón el ser y lo uno son géneros comunes a todas las cosas y, como todo universal, tienen una existencia separada o hipostasiada, lo cual equivale a afirmar que son sustancias cuya esencia es exclusivamente el ser y lo uno. Pero en cuanto que son géneros, el ser y lo uno son principios y elementos de todas las cosas; más exactamente, son géneros supremos porque son predicables de todas las cosas (Berti, 1979).

Ahora bien, en Santo Tomás se encuentran al menos tres nociones que a simple vista podrían evocar los planteamientos platónicos aludidos: la admisión de sustancias simples o separadas, el concepto de esse commune, y su doctrina de la participación en el ser-de reconocida filiación platónica (González Álvarez, 2001).

Con relación a la primera de esas nociones, basta con advertir que desde los comienzos de su carrera académica, el Aquinate asume con acento inequívoco la existencia de sustancias intelectuales o simples, esto es, no compuestas de materia y forma porque en ellas la forma no es recibida en materia alguna (non recepta in aliqua materia). No obstante, en dichas sustancias una cosa es el ser y otra la esencia (in quibus est aliud esse quam essentia earum) (Tomás de Aquino, trad. 2001a, 4). A diferencia de Dios cuya esencia se identifica con su ser, las formas subsistentes finitas participan en el esse. Esto último remite a las otras nociones enunciadas.

Como es ampliamente conocido, Tomás de Aquino utiliza de manera reiterada la expresión esse commune para referirse al esse creado que actualiza intrínsecamente a todos y cada uno de los entes finitos, y que, por tanto, existe de manera real sólo en ellos. Como ser separado, enfatizará el Aquinate, sólo puede existir en la mente, esto es, en tanto que pensado. Dicha idea queda expuesta con total claridad en Contra Gentiles (Tomás de Aquino, 2005, 1.26), donde declara que Dios no es el esse formal de todas las cosas, o el ser por el cual todas las cosas son. Porque, como razona en uno de sus argumentos, lo que es común a muchos (por ejemplo, animal) no existe como tal aparte de ellos (éste o aquel animal), excepto en el pensamiento, es decir, si se habla de un esse común es porque todas las cosas, en tanto que existen, tienen en común (coinciden en) poseer un principio intrínseco que les confiere la existencia, las hace ser. Fuera de las realidades que actualiza, el ser común no existe; sólo posee una existencia conceptual o lógica, por consiguiente, no es real (Pérez Guerrero, 1996). De modo que si Dios se identificara con el esse commune, entonces existiría sólo en el orden del pensamiento Tomás de Aquino, trad. 2005, 1. 26; 2000-2009e, 7. ad. 4; trad. 1954-1960, 1. 3.4. ad.1; Wippel, 2000). 
Ahora bien, es necesario apuntar que el Aquinate en un pasaje de su comentario al $D e$ Divinis Nominibus del Pseudo-Dionisio (Tomás de Aquino, 2000-2007h, 51.2), se refiere a una doble participación: en el esse communne, y en el esse subsistens (lo cual, si no se interpreta de manera correcta, podría estar dando la razón a la tesis de Berti y Kenny), pero tal como infieren J. Pérez Guerrero (Pérez Guerrero, 1996) y J. Wippel (Wippel, 2000), las ideas allí relacionadas por el Aquinate permiten concluir que la criatura es ente porque participa del ser común, aunque el ser común supone cierta participación en el Esse subsistens; esto es, tener ser (o ser un ente) implica participar por semejanza o asimilación en el Primum et Purum Actum (Tomás de Aquino, 2000-2009b, 1 y 2000-2009e, 12.4.1; Wippel, 2007). Santo Tomás armoniza así la participación en el esse y la participación en el esse subsistens al presentarlas como de suyo inseparables, salvaguardando, a su vez, la distancia ontológica infinita que existe entre el ser creado y el ser increado. Es lo que ha visto Javier Pérez Guerrero (1996) al afirmar que “... si no queremos otorgar al ser creado la categoría de tercera realidad mediadora entre Dios y las criaturas, y alejarnos con ello del pensamiento de Santo Tomás, debemos fundir las dos participaciones en una sola, pues sólo hay un sujeto participante que es la criatura. Así, el carácter medial del ser creado o ser común, debe entenderse como la articulación de los dos momentos que se nos ofrecen: el momento criatura-ser común y el momento ser común-ser divino; $\mathrm{y}$, de este modo, se puede solucionar válidamente el problema planteado en relación a la incomunicabilidad del ser divino". (pp. 64-65).

Dicha incomunicabilidad se salva porque la participación del ser creado (esse commune) y, por tanto, del ente en el esse subsistens se da, tal como enseña el Aquinate, por vía de semejanza o asimilación. Es posible afirmar que es precisamente este modelo de participación el que mejor permite eludir el equívoco que supone entender el ipsum esse como ser separado.

Desde otro enfoque argumentativo, L. Dewan (Dewan, 2005) parece arribar a la misma conclusión. Refutando la afirmación de Kenny según la cual el ser que se identifica con Dios es el esse común a todos los entes, el profesor Dewan (2005) escribe: "Obviamente eso no es lo que se dice allí (en De Sub. Sep.). En Dios el esse es universal, y en las criaturas es particular. Hay una unidad de ratio por analogía, como se enseña por ejemplo en S.Th. I, q.4, a.3” (p. 398). En el contexto explicativo de otros pasajes del Aquinate, más adelante concluye: "Esto es lo que Tomás está diciendo in De substantiis separatis, que Dios es ser mismo al modo de causa universal de la existencia. Esta es su doctrina desde el comienzo hasta el final de su carrera". (Dewan, 2005, p. 399).

El problema no radica, entonces en afirmar que para Tomás de Aquino existen perfecciones que subsisten de modo separado, ni siquiera en sostener que su doctrina de la participación reconoce evidentes raíces platónicas, como de hecho sucede. De lo que se trata es de dilucidar si es válido mantener que la fórmula ipsum esse subsistens, simplemente expresa que en Dios se da de modo separado en una perfección (el ser) que en las criaturas se da de modo compuesto, es decir, en composición con la esencia. El núcleo de la cuestión consiste sustancialmente en preguntarse si es correcto "considerar a la separación y a la composición como diferentes estados de una misma perfección" (Pérez Guerrero, 1996, p. 27), que es lo que sugiere la idea del ser separado, esto es, "supone la idea de una perfección común a Dios y a la criatura: de una perfección que en Dios se encuentra de modo separado y en la criatura de modo inherente" (Pérez Guerrero, 1996, p. 33).

Es justo resaltar de antemano la contundente negativa de un tomista de la talla de S. Brock a ese interrogante: "... el ser divino no se puede concebir como la mera versión 'separada' del mismo ser común. Es un ser que está 'más allá' del ser mismo" (Brock, 2005, p. 25; 2004, pp. 211-212).

Sin embargo, tal como ha sido tradicionalmente interpretada, en la participación por 
composición la misma perfección (en este caso el ser) se presenta bajo un doble estado: como lo imparticipado e ilimitado (el ipsum esse) y como algo inmanente a los entes creados que reciben o participan de dicha perfección. Por tanto, estos poseen la misma perfección si bien no en toda en su plenitud, sino participada y limitadamente como resultado de una composición (con la esencia o capacidad del entre creado para recibir dicha perfección). Entre participante y participado (lo en sí) no habría más que una diferencia de grado: la misma perfección (el esse) que se da de modo pleno en el ipsum esse, se presenta degradada en las criaturas.

En efecto, eso es lo que entienden Berti y Kenny cuando asimilan el ipsum esse subsistens a la Idea platónica de ser: lo conciben como el ser separado. El ser que, en las criaturas existe limitado y determinado por su modo de ser específico, en Dios aparecería como el ser separado, esto es, el ser mismo sin cualificación. Se trataría, por tanto, de un ser unívoco, uniforme, que existiría bajo dos estados: en Dios de modo separado, por ende, absolutamente libre de composición. En los demás entes encontraríamos este mismo ser, pero no ya en estado puro, sino en composición con la esencia de cada ente particular.

Se puede afirmar que los textos del Aquinate leídos en el contexto de su filosofía del ser y de su metafísica de la creación no autorizan tal interpretación sino que, por el contrario, permiten colegir que "el ser no es, que algo así como el ser no existe y, en este sentido, tampoco lo hay. Ipsum enim esse nondum es" (Inciarte y Llano, 2007, p. 235). En efecto, Santo Tomás es muy claro en afirmar que el ser concebido de manera abstracta no es. Sólo es el existente individual, el que ha recibido o participa en el acto de ser (Tomás de Aquino, 2000-2009c, 16; Brock, 2005).

\section{El ser y su ser}

J. Pérez Guerrero en su examen lúcido de los textos de Santo Tomás alrededor de la creación como asimilación a Dios, ofrece una explicación de la participación por semejanza que parece sumamente relevante en orden a esclarecer el tema que nos ocupa. Asimismo, cabe resaltar que la interpretación sugerente del autor difiere de manera sustancial de la clásica participación por semejanza de Geiger (Pérez Guerrero, 1996).

El núcleo de la tesis de Pérez Guerrero puede resumirse así: en la participación por similitud, según la cual la criatura se asimila a Dios por el ser (Tomás de Aquino, trad. 2005, II, 53), el ser de la criatura se identifica con la propia asimilación a Dios: "ser', aquí significaría lo mismo que 'asimilarse a Dios" (Pérez Guerrero, 1996, p. 80). El participar (el asimilarse a) sólo puede tener un carácter activo: "La criatura no actúa como recipiente del acto creador: para la criatura, recibir de Dios no es ganar algo que le falte sino ganancia pura. El acto creado es intrínsecamente relativo al acto creador: tiene de acto lo que tiene de 'deducido' del acto divino. Por eso se interpreta como un acto de asimilación a Dios" (Pérez Guerrero, 1996, p. 77).

La distancia irreductible que separa el ser de la criatura del ipsum esse aparece expresada aquí en toda su radicalidad. Este análisis pone de relieve que en realidad no hay nada semejante entre criatura y Creador, tampoco el ser. Es lo que han percibido F. Inciarte y A. Llano al afirmar que "El mundo es semejanza de Dios sin que entre ambos se dé semejanza alguna, por lo menos mutua" (Inciarte y Llano, 2007, p. 360). Y esto es así porque ser creado es ser de la nada; "pero como la nada no existe, eso no significa sino que la creación no es nunca a partir de algo... Lo importante de verdad es ver que la nada sigue operando incluso cuando 'ya' hay algo; ver que ese algo caería 'otra vez' (un modo de decir) en la nada si todo quedara ahí, si sólo fuera eso lo que hay y si eso no siguiera siendo" (Inciarte y Llano, 1996, p. 351).

Entender de este modo la creación ayuda a despejar los equívocos que se han generado en torno a la doctrina del ipsum esse y sus relaciones 
con el ser de la criatura. Ciertamente, bajo esta perspectiva resulta más difícil caer en la tentación de uniformar el ser. Sin duda, cuesta concebirlo como algo "compartido" de manera graduada por Dios y las criaturas cuando se comprende de verdad que "lo que el mundo posee de suyo, lo propio del mundo, es la nada. Lo que es, es sólo de Dios" (Inciarte y Llano, 2007, p. 358).

Pues bien, nos parece que el Aquinate al recurrir a expresiones como la que hemos venido analizando (ipsum esse subistens) se enfrenta con la limitación del lenguaje humano para expresar la absoluta inconmensurabilidad que separa a Dios de los entes creados. De ahí que, seguramente movido por la preocupación de formular del modo más explícito posible ese abismo ontológico infinito, utilizará incluso con mayor frecuencia la expresión Deus est suum esse (Tomás de Aquino, 2000-2009g, 1.8.5.2; trad. 2005, 1.28, 1.47, 1.65; trad. 1954-1960, 1.10.2; 1.14.14.2; 1.18.3.2; trad. 2001b, 21.4.7).

Es más, en alguna ocasión vincula directamente ambas expresiones al hacer uso de la fórmula "ipse Deus est suum esse subsistens" (Tomás de Aquino, 2000-2009f, 1.8.3.3; trad. 2005, 1.52; trad. 2001b, 21.5; trad. 1954-1960, 1.12.4).

En nuestra opinión nombrar a Dios como $s u$ ser (suum esse), por un lado, permite evitar las ambigüedades que implica traducir ipsum esse subsistens como "el ser mismo subsistente". Bajo este aspecto, conviene no perder de vista una simple cuestión gramatical que, sin embargo, puede revestir una importancia decisiva a la hora de entender el pensamiento del Aquinate. Tomás, señala Brock, escribía en latín que no utiliza artículos. Por tanto, cuando escribe Deus est ipsum esse, ¿debemos dar por descontado que Dios es el ser mismo? Tal traducción, afirma dicho autor, es ya una interpretación platonizante. Se debería traducir, Dios es un ser mismo o un ser mismo que subsiste per se (Brock, 2004). Esto sería más cercano al pensamiento de Tomás de Aquino.

Por otro lado, mantener que Dios es su ser mismo expresa con mayor nitidez la convicción de
Aquino acerca de que Dios no puede estar en un género, del cual los seres creados serían especies, partes específicamente determinadas del mismo ser (Brock 2004), puesto que su ser es propio de él (Tomás de Aquino, trad. 2001b, 21.4.7). Un esse, enseña S. Brock, "que es divino; y en esto es único, desde que ninguna otra sustancia tiene una esencia que es idéntica con su propio ser" (Brock, 2007b, p. 483). Porque aunque las demás cosas también tienen su ser, este ser no es el ser divino (Brock, 2005). El ser de las criaturas está determinado conforme a su propia ratio, es decir, de acuerdo con la ratio misma de 'esse"', (Brock, 2007b, p. 482). Por el contrario, el ser de Dios que es idéntico con la plenitud de la perfección del ser (ipsum esse subsistens) (Tomás de Aquino, 2000-2009a, 1.215) no queda, en modo alguno, circunscrito o limitado por la ratio de esse. En efecto, "La naturaleza o esencia del esse divino está más 'allá' de la esencia del esse mismo” (Brock, 2007b, p. 483).

Sólo Dios es plenamente su propio ser (Tomás de Aquino, 2000-2009b, 1), esto equivale a afirmar que su esencia incluye todas las perfecciones que caen bajo la naturaleza del ser $\mathrm{y}$, al mismo tiempo, las sobrepasa porque el ser divino contiene todas las perfecciones de las cosas y el esse no es la única perfección (Brock, 2007b). Sobre la base de este aserto, no es posible confundir el ipsum esse subsistens con una idea platónica de esse. La naturaleza propia y exclusiva de Dios es diversa de la naturaleza del esse commune, del ser mismo o la ratio de ser tal como se presenta en las criaturas (Brock, 2007b). Si ambas naturalezas se identificaran, observa S. Brock (Brock, 2007b), el ser de Dios "no sería causa del esse mismo, especialmente una causa que trasciende el efecto; porque el esse mismo sería sólo eso que es" (p. 483).

El principio de no-plenitud (Llano, 1994, p. 24) de los entes contingentes sirve igualmente para iluminar el alcance semántico de la fórmula Deus est suum esse. Y es que en la medida que se considera el carácter de no-ser relativo (Wippel, 2007) propio de la criatura, resalta con mayor nitidez la plenitud ontológica de El que es (Inciarte y Llano, 2007). 
Así lo han advertido con notable penetración F. Inciarte y A. Llano. De Dios, "aquel ser que es plenamente él mismo" (Inciarte y Llano, 2007, p. 236), cabe afirmar "-con una expresión de Nicolás de Cusa- que es el possest, es decir, el que es todo su poder, toda su capacidad, todo su posse: "En él coinciden posibilidad y realidad" (Inciarte y Llano, 2007, p. 236). En la criatura, en cambio, lo que es (su esencia) se distingue realmente de su acto de ser. Esto significa que en el ente creado, todo lo que él es no se identifica con su acto de ser, por tanto, nunca llega a ser plenamente hoy todo lo que es. Las perfecciones intrínsecas a su esencia tienen la posibilidad real de realizarse de manera efectiva, pero también la de no actualizarse nunca: “. . . fuera del Ens necessarium nada es en rigor del todo necesario (ni del todo contingente). En diversas 'proporciones', todas las cosas tienen una dimensión de relativa plenitud -su esencia o modo necesario de ser-, que es paradójicamente compatible con su dimensión de noplenitud: su no ser plenamente lo que son, su poder ser de otra manera" (Llano, 1997, p. 237). Los entes creados no son plenamente lo que son en efecto, porque no son su ser, sino algo (Inciarte y Llano, 2007).

Recordemos por último, otra de las objeciones aducidas por Berti y Kenny contra la fórmula ipsum esse subsistens. En opinión de ambos autores, con dicha expresión, Aquino está indicando que el ser de Dios es algo indeterminado, sin cualificación. Porque afirmar que la esencia de Dios es su existencia representa, sostiene Kenny, una fórmula deficiente, incompleta, carente de predicado (Kenny, 2002).

El contexto explicativo que hemos desarrollado hasta aquí permite extraer conclusiones que contradicen abiertamente ese planteamiento. Sin duda, Santo Tomás al enseñar que Dios es $s u$ ser es plenamente consciente de que la plenitud de perfección del ser divino resulta imposible de aferrar con los recursos finitos del entendimiento y del lenguaje humanos.

No obstante, intenta expresarlo con los términos que mejor puedan manifestar que él es el ser superlativamente cualificado. De ahí que cuando Tomás afirma que Dios es su ser con esa expresión está remarcando su diversidad (Tomás de Aquino, 2000-2009g, 8.1.2.3) radical respecto de los demás entes. Porque el ser divino es el único ser individualizado por sí mismo (Gilson, trad. 1969), la individuación máxima es atributo exclusivo de él. Sólo aquel ente cuya esencia se identifica con su ser puede reunir todas las perfecciones de su ser (Tomás de Aquino, trad. 1954-1960, 1.4.3):

“... el único caso en que el 'ser' es absolutamente puro de toda adición o determinación es también el único caso en que el ser es absolutamente distinto de todo lo demás. Dios no debe su esse a su propia individualidad; sino que más bien, a Él pertenece necesariamente la individualidad suprema y única, y Él es Él, precisamente porque sólo Él es el 'ser' en su absoluta pureza: "Unde per ipsam suma puritatem est esse distinctum ab omni esse (De ente et essentia., cap. VI, IV)". (Gilson, trad., 1996, p. 231).

Llegados a este punto de nuestro estudio, encontramos otro principio inspirador que parece dominar el espíritu y la filosofía del Aquinate. Aún pudiendo admitir la especificación absoluta y perfecta del ser de Dios, con todo, permanece desconocido para nosotros el contenido de esa individuación (Gilson, trad., 1996). La plenitud de ser y perfección de la esencia divina no puede quedar expresada de modo definitivamente comprensivo en ninguna palabra nuestra, tampoco la palabra ser (Brock, 2005).

Aunque Tomás de Aquino ha dedicado gran parte de su obra a indagar la naturaleza de Dios con una finura intelectual y un rigor argumentativo incomparables, no obstante nos enseña que es necesario permanecer profundamente conscientes de los riesgos que encierra pretender expresar lo inefable. Nos advierte, así, que "En último término, no hacemos más que proceder a la aclaración y enriquecimiento semántico de lo que significa 'Dios', sin llegar a alcanzar lo que realmente es en sí mismo: bajo este último respecto, hemos de conformarnos con la philosophia negativa" (Llano, 1997, p. 188, nota 131). 


\section{Su ser, filosofía negativa y metafísica mínima en Tomás de Aquino}

La doctrina del ipsum esse subsistens nos ha llevado al tema conclusivo con el que pretendemos cerrar el presente ensayo; se trata de dejar simplemente sugerida una triple intuición. Nos parece que, por un lado, existen importantes aspectos de la metafísica de Tomás de Aquino que permiten describirla como una filosofía negativa. Por otro lado, pensamos que esta dimensión poco explorada de su pensamiento puede ofrecer una herramienta hermenéutica clave para penetrar "el espíritu" de su filosofía del ser. Por último, es posible que si logramos dar con el espíritu que palpita en su vasta obra, encontremos (por paradójico que esto resulte) que, en el fondo, el Aquinate sólo se propuso desarrollar una metafisica mínima. De ser así, esta metafísica mínima de Tomás de Aquino ofrecería el entramado conceptual adecuado para repensar elementos de su filosofía-tal como el ipsum esse subsistens- con frecuencia desgastados, tal vez, a fuerza de abordarlos bajo una clave de interpretación ajena al sobrio realismo del Aquinate.

Es ampliamente admitido un aspecto central de la teología de Santo Tomás conocido como teología negativa, expuesta de manera nítida por célebres pasajes en los cuales Aquino advierte que el supremo conocimiento humano de Dios consiste en saber que, en la medida en que conocemos, no alcanzamos a Dios; que Dios está más allá de todo lo que sabemos de él (Tomás de Aquino, 2000-2009e, 7.5. ad. 14). Se podría destacar como nota característica de este modo de concebir la teología, el hecho de que revela una actitud cautelosa y, a la vez, confiada frente al conocimiento de Dios.

Como ha observado Gilson (trad. 1969), "El propósito de la doctrina de Tomás de Aquino sobre este punto crucial es invitarnos a una especie de ascética intelectual calculada para librar nuestros intelectos del engaño de que sabemos lo que es Dios" (pp. 141-142). Pero como él mismo señala, aunque "El resultado final necesariamente será, por consiguiente, imperfecto, pues no nos dirá lo que Dios es en sí mismo. Al mismo tiempo será un verdadero conocimiento de Dios, puesto que nos hará conocerlo 'como distinto de todos los demás seres" (Gilson, trad. 1969, p. 143).

Sin embargo, no es fácil calar en esta actitud intelectual de Tomás de Aquino. En términos generales, solemos oscilar entre la ilusoria pretensión racionalista de querer encerrar a Dios en un sistema y el escepticismo agnóstico que renuncia de antemano a todo conocimiento sobre Dios. Un claro ejemplo de que la suya no es una teología negativa radical lo constituye el siguiente pasaje de la Suma Teológica (Tomás de Aquino, trad. 1954-1960):

“... hay que decir que todos estos nombres expresan la sustancia divina y se predican de Dios sustancialmente, si bien no la expresan totalmente. Esto es así por lo siguiente. Estos nombres expresan a Dios tal como nuestro entendimiento lo conoce. Y nuestro entendimiento, en la medida en que le conozca a partir de las criaturas, así le conoce, por cuanto las criaturas le representan. Se demostró (q.4 a.2) que Dios contiene todas las perfecciones de las criaturas, pues El es simple y absolutamente perfecto. De ahí que cualquier criatura le representa y le es semejante en la medida en que tiene alguna perfección. Sin embargo, no le representa como algo de su misma especie o género, sino como principio sublime, de cuya forma carecen los efectos, pero que, sin embargo, albergan alguna semejanza, como sucede con los cuerpos de aquí abajo que, de alguna manera, representan la fuerza solar. Esto ya se expuso anteriormente cuando se trató la perfección divina (q.4 a.3). Así, pues, los nombres señalados expresan la sustancia divina, si bien imperfectamente, por cuanto las criaturas la representan imperfectamente.”(I. 13.1).

No en vano se ha señalado, por ejemplo que este aspecto del pensamiento del Aquinate -el de su teología negativa- es poco atendido precisamente por Kenny en Aquinas on Being (Davies, 2005 ). 
J. Pieper es uno de los autores -junto con A. Llano- que no sólo ha hablado de una teología negativa en Tomás de Aquino, sino también de una filosofía negativa ("the negative element' in St. Thomas's philosophy") (Pieper, trad. 1999, p. 64) cuya esencial característica radica en que sus preguntas apuntan a respuestas que no pueden ser dadas adecuadamente (Pieper, trad. 2000). Al expresarse de este modo, Pieper se apoya en algunos pasajes en los que el Aquinate expone su filosofía mediante proposiciones negativas, tal como la conocida "rerum essentiae sunt nobis ignotae (Tomás de Aquino, trad. 2001b, 10.1).

Según Pieper (trad. 1999), es la noción de creación la que determina todo el entramado de la filosofía del ser del Aquinate y, particularmente este elemento negativo de la misma. "Las cosas son insondables porque son creadas" (Pieper, trad. 1999, p. 57), esto es, nunca podremos penetrar definitivamente la última realidad de las cosas porque nunca aprenderemos plenamente su semejanza con las Ideas divinas conforme a las cuales han sido creadas (Pieper, trad. 1999). Bajo esta perspectiva, la limitación no está en lo conocido sino que procede de la inteligencia finita, incapaz de abarcar el misterio del ser.

Fuera de que asumimos como nuestra la tesis penetrante de Pieper, quisiéramos añadir otra dimensión, quizá más profunda, según la cual las cosas también pueden considerarse desconocidas porque son creadas. En el análisis precedente hemos tenido oportunidad de contraponer la plenitud de su ser (exclusiva de Dios) al ser limitado de las criaturas que nunca son plenamente lo que son porque "están entrecruzadas de no ser, por tanto de indeterminación" (Llano, 2006). En efecto, esta defíciencia de lo finito con relación a sí mismo es lo que explica, en parte, el que las cosas nunca pueden ser plenamente conocidas por nosotros:

"Lo dicho significa que lo finito es deficiente respecto a sí mismo. No se trata solamente de que se diferencie de todo lo demás -de lo infinito, así como de todo lo finito, que no es plenamente lo que es- sino que también se diferencia de sí mismo. De esta manera, la identidad de lo finito consigo mismo -y la identidad de cada cosa en el interior de sí misma respecto a sí misma- no se elimina, sino que se indica lo débil de esta identidad. Pues no sólo todo lo que es -la realidad- tiene grados, sino que también los tiene la identidad, la cual acontece sólo en grados; prescindiendo en este momento del grado más alto de identidad, que por lo demás trasciende toda gradualidad y está fuera de la escala, porque es la identidad misma." (Inciarte y Llano, 2007, p. 245).

Sea por la escasez (la no-plenitud) o por la abundancia de su objeto, la metafísica está llamada a ser mínima, a ser "escueta" y hablar de muy pocas cosas (que son, sin embargo, las fundamentales -los primeros principios o conceptos-). Porque el mundo no es pleno, la metafísica no puede explicarlo todo. Pero mucho menos puede pretender ser exhaustiva cuando lo que estudia es el ser divino. Se comprende, así, que si se ha escrito tanto sobre metafísica en general y sobre Dios en particular es porque no acertamos a decirlo (Llano, 2006).

Con todo, el problema no radica en la mayor o menor extensión de nuestros escritos, sino en pretender encerrar la totalidad del ser en nuestras categorizaciones que son más propias de la lógica que de la filosofía y, por lo mismo, un rasgo distintivo de los sistemas filosóficos cerrados. Tomás de Aquino, que ha escrito mucho y muy bien sobre Dios, logró escapar a la tentación fáustica de un saber total. La suya es una teología natural mínima. Pensar otra cosa, demuestra que no se ha entendido al Aquinate. Por eso, de ningún modo es válido interpretar que pretenda develarnos la esencia de Dios a través de fórmulas como Dios es ipsum esse subsistens. Tomás es muy claro en enfatizar que no podemos comprender el ser de Dios como tampoco su esencia (Brock, 2007a). En este sentido L. Dewan (2005) ha resaltado con penetrante lucidez que: "Uno no supone que sea posible imaginar esto [un puro ser o ipsum esse] como tal; un puro ser no es objeto de la imaginación. En efecto, al igual que sucede con la esencia de Dios, la lección 
constante es que un ser puro es humanamente inconcebible. Sabemos que hay tal cosa, pero no lo sabemos en el sentido de que conocemos 'lo que esta cosa es"” (p. 380).

La filosofía del ser de Santo Tomás ofrece principios fundamentales (mínimos) y un elemento negativo que se avienen con esta metafísica "escasa de contenidos y abundosa de radicalidad" (Inciarte y Llano, 2007, p. 22). Precisamente, tal vez, sea este un ejercicio que deba ser tomado más en serio nosotros los seguidores del Aquinate. Se trata de la tarea de retomar y sopesar tesis fundamentales de su metafísica desprendiéndonos de clasificaciones y distinciones a priori. En este empeño nos estimula también la libertad y amplitud de su espíritu genuinamente filosófico, cuya preocupación fundamental nunca fue "lo que piensan los hombres, sino cuál es la verdad de las cosas" (Tomás de Aquino, 2000-2009d, 1.22.8).

\section{Referencias}

Aquino, Tomás de (2005). Suma contra los gentiles (2 vol.). Ed. bilingüe dirigida por L. Robles Caicedo, O.P. y A. Robles Sierra, O.P. Madrid: B.A.C.

Aquino, Tomás de (1950-1964). Suma teológica (16 vol.). Texto latino de la edición crítica Leonina. (Trad. y anotaciones por una comisión de los PP. Dominicos presidida por F. Barbado Viejo O.P.). Madrid: B.A.C.

Aquino, Tomás de (2001a). El ente y la esencia. En Opúsculos y obras selectas (1 vol.). (Trad. y anotaciones por una comisión de los PP. Dominicos presidida por A. Osuna Fernández-Largo O.P.). Madrid: B.A.C.

Aquino, Tomás de (2001b). De veritate. En Opúsculos y obras selectas (vol. 1). Madrid: B.A.C.

Aquino, Tomás de (2000-2009a). Compendium Theologiae. En Corpus Thomisticum. http:/ /www.corpusthomisticum.org/
Aquino, Tomás de (2000-2009b). De Spiritualis Criaturis. En Corpus Thomisticum. http:// www.corpusthomisticum.org/

Aquino, Tomás de (2000-2009c). Expositio libri Boetii De ebdomadibus. En Corpus Thomisticum.http://www.corpusthomisticum.org/

Aquino, Tomás de (2000-2009d). In libros De caelo et mundo. En Corpus Thomisticum. http://www.corpusthomisticum.org/

Aquino, Tomás de (2000-2009e). Queastiones Disputatae De Potentiae. En Corpus Thomisticum.http://www.corpusthomisticum.org/

Aquino, Tomás de (2000-2009e). Queastiones de Quoadlibet. En Corpus Thomisticum. http:/ /www.corpusthomisticum.org/

Aquino,Tomás de (2000-2009g). Scriptum Super Sententiis. En Corpus Thomisticum. http:// www.corpusthomisticum.org/

Aquino, Tomás de (2000-2009h). Super De divinis nominibus. En Corpus Thomisticum. http:/ /www.corpusthomisticum.org/

Aristóteles. (1994). Metafisica. (Trad. T. Calvo Martínez). Madrid: Gredos.

Berti, E. (1984). L'analogia dell'essere nella tradizione aristotelico-tomistica, in Metafore dell'invisible: Richerche sull'analogia, Contributi al XXXVIII Convegno del Centro di Studi filosofici di Gallarate. Morcelliana: Brescia, pp. 13-33.

Berti, E. (1979). Le problème de la substantialité de l'être e de l'un dans la Métaphysique, in Études sur la Métaphysique, edition au soin de P. Aubenque, J. Paris : Vrin (versión francesa del original italiano: Il problema della sostanzialità dell'essere e dell'uno nella Metafisica di Aristotele, in E. Berti, 
Studi Aristotelici, Japadre Editores, L'Aquila, 1975, pp. 181-208).

Berti, E. (2001). Multiplicity and Unity of Being in Aristotle. Proceedings of the Aristotelian Society, pp. 185-207.

Brock, S. (2004). L'ipsum esse é platonismo?, in Tommaso D'Aquino e l'oggetto Della metafisica. Roma: Armando Editore.

Brock, S. (2005). La 'conciliazione' di Platone e Aristotele nel commento di Tommaso D'Aquino al De Hebdomadibus. Acta Philosophica, I.

Brock, S. (2006). "On whether Aquinas's Ipsum esse is "Platonism"'. The Review of Metaphysics LX, pp. 269-303.

Brock, S. (2007a). Comunicación personal vía e-mail, octubre 2007.

Brock, S. (2007b). Harmonizing Plato and Aristotle on Esse: Thomas Aquinas and the De hebdomadibus. Nova et Vetera, 5/3.

Davies, B. (2005). Kenny on Aquinas on Being. The Modern Schoolman, LXXXV.

Dewan, L. (2005). Discussion On Anthony Kenny's Aquinas on Being. Nova et Vetera III-2(2005), pp. 335-400.

Gilson, E. (1969). Elementos de filosofia cristiana. (Tr. A. García-Arias). Madrid: Rialp.

Gilson, E. (1996³). El ser y los filósofos. (Tr. S. Fernández Burillo). Pamplona: EUNSA.

González Álvarez, A. (20013). Ser y participación. Estudio sobre la cuarta vía de Tomás de Aquino. Pamplona: EUNSA.

Inciarte F. \& Llano, A. (2007). Metafísica tras el final de la metafisica, Madrid: Ediciones Cristiandad.
Kenny, A. (2002) Aquinas on Being. Oxford: Clarendon Press.

Klima, G. (2004). On Kenny on Aquinas on Being: A critical Review of Aquinas on Being by Anthony Kenny. International Philosophical Quarterly, XLIV/4.

Llano, A. (1994). Aquinas and the Best Possible World, in The Aquinas and his Legacy. D.M. Gallagher (Edit). Studies in Philosophy and the History of Philosophy, Washington: The Catholic University of America Press, vol. 28.

Llano, A. (1997). Metafísica y lenguaje. Pamplona: EUNSA.

Llano, A. (2006). Apuntes no publicados del Seminario sobre Metafísica tras el final de la metafísica. Bogotá: Universidad de La Sabana, 4-15 de septiembre.

McGinnis, J. (2005). The Avicennan Sources for Aquinas on Being: Supplemental Remarks to Brian Davies" "Kenny on Aquinas on Being". The Modern Schoolman, LXXXII.

Pérez Guerrero, F.J. (1996). La creación como asimilación a Dios. Un estudio desde Tomás de Aquino. Pamplona: EUNSA.

Pieper, J. (1999). The silence of St. Thomas. (Tr. By J. Murray and D. O'Connor). Indiana: St. Augustine's Press.

Pieper, J. (2000). El misterio y la filosofía. En Obras, Vol. 3: Escritos sobre el concepto de filosofía. (Tr. J. Hernández-Pacheco). Madrid: Ediciones Encuentro.

Wippel, J. (2000). From Finite Being to Uncreated Being. Washington D.C,: The Catholic University of America Press.

Wippel, J. (2007). Metaphysical Themes. Washington D.C: The Catholic University of America Press. 
